\title{
Article \\ On the Acceptability and Use of -ra and -se in Conditional Phrases in Galician Spanish
}

\author{
Ana Maria Anderson
}

Spanish Writing Center, Franklin \& Marshall College, Lancaster, PA 17604, USA; ana.anderson@fandm.edu; Tel.: +1-651-285-1554

Academic Editors: Anel Brandl and Lara Reglero

Received: 22 July 2017; Accepted: 4 October 2017; Published: 13 October 2017

\begin{abstract}
The verb forms ending in -ra and -se in modern Spanish both correspond to the imperfect subjunctive, but their use is far from equal throughout the Spanish-speaking world. Rojo (1996) documents that the -se form is all but obsolete in the majority of American nations, and Kempas (2011) records rates of use in Spain ranging from $11 \%$ to $44 \%$. The highest rate corresponds to usage patterns in Galicia, where contact with the regional language, Galician, may provide a conservative influence with respect to the shift from -se to -ra. The present study considers the effects of age, sex, and primary language, as well as linguistic factors such as possibility of the event (i.e., Lavandera (1975)) on the acceptability and choice of -se or - $r a$ in the protasis of conditional statements in Galician Spanish. To accomplish this, 29 speakers completed an online acceptability rating task of 24 statements with varying combinations of verb forms in the protasis and apodosis. They were asked to correct those statements that they rejected as incorrect and unused in their own speech, and their produced corrections were compared to their acceptance or rejection of forms in the models. Results indicated that neither social factors nor possibility significantly affect the acceptance of phrases in -ra or -se. However, individual idiosyncrasies do affect the production of these verb forms, in line with results from Kempas (2011) and Rojo and Vázquez Rozas (2014).
\end{abstract}

Keywords: Galician Spanish; language contact; subjunctive

\section{Introduction}

Though the verb forms ending in -ra and -se in modern Spanish both correspond to the imperfect subjunctive, this is not the original distribution of these forms. In Latin, the -ra form marked the simple pluperfect indicative, while -se corresponded to the pluperfect subjunctive [1]. Over time the two forms gradually lost their perfective association and the -ra form came to be associated with subjunctive values, though it did not completely lose all of its indicative associations [1,2]. Forms in -se and $-r a$ are commonly considered equivalent and interchangeable in normative Spanish in almost all contexts [3,4], despite some debate of this point [5,6]. This is evidenced in (1), in which one participant responded to the phrase Si yo ganaría la lotería me compraría un coche nuevo 'If I would win the lottery I would buy myself a new car' by including both ganara 'to win' and ganase 'to win (alternate form)' in the suggested correction.

1. Si yo ganase/ganara la lotería, me compraría un coche nuevo.

M5, from Vigo

'If I were to win the lottery, I would buy myself a new car.'

Two exceptions to this equivalence are the modal verbs (i.e., quisiera hablar con el dueño 'I would like to speak to the owner'), in which the -se form is not permissible (though the conditional querría 'would like' would be accepted), and the few indicative uses of the -ra form, most commonly found in journalistic language [2]. The nearly complete convergence of $-s e$ and $-r a$ has led to a steady 
restructuring of the verb form used to mark imperfect subjunctive, with the -ra form replacing the -se in most areas of the Spanish speaking world, though this shift has not been uniform in all regions.

While the -se form predominated in Spain in the early 20th century, by 1973 Gili Gaya reported that $-\mathrm{ra}$ had become the dominant form in literary and in educated spoken language [7]. Even so, average rates of use of -se in periodicals were still around 30\% in Navarre in 1976 [8]. In 1975 Buenos Aires, however, Lavandera found that only approximately $12 \%$ of verbs in her oral sample used the -se form, and in a compared written corpus this rate was only 8\% [9]. Similarly, by 1978, Moreno de Alba reported less than $4 \%$ use of -se in Mexico, and Navarro in 1990 noted that -se was used in $9.2 \%$ of possible -se/-ra alternation contexts in Valencia, Venezuela $[10,11]$. Spain has retained the traditional form at a higher rate than has Latin America, but this retention is still minimal in most areas: Rojo verified almost complete disappearance of the -se variant in the Americas, while Spain still maintained an average of $18.4 \%$ usage [12]. Spain itself has progressed far from homogeneously, however, as Rojo's data ranged from a low of $0 \%$ usage in urban Sevilla to highs of $20 \%$ or more in other regions such as Madrid.

It is in Galicia, the northwestern-most region of Spain, where the conservation of -se appears to be strongest. Kempas found $44.4 \%$ use of -se in the region, and Rojo and Vázquez Rozas reported more than $27 \%$ use of the same form $[2,13] .{ }^{1}$ This increased use may be related to contact in the region between Spanish and the local language, Galician. Indeed, one feature of the Galician verb system that distinguishes it from Spanish is the normative use of the -ra form as the simple pluperfect indicative, leaving -se as the only (normative) form of the imperfect subjunctive. ${ }^{2}$ Thus the Galician system is more conservative, in the sense of being closer to the original Latin, and may exert a conserving influence on the Spanish of the region as well.

The purpose of the present study is to further investigate variation in the choice and acceptance of the two imperfect subjunctive forms in Galician Spanish. To facilitate this analysis, the forms considered here are limited to hypothetical si-clauses, though it is recognized that there are many other contexts for variation that can and should be studied in order to obtain a more complete picture of -se/-ra variation in the region.

In her 1982 study of a distinct yet related phenomenon, Silva-Corvalán compared two hypotheses about the motivation behind the extension of the conditional to imperfect subjunctive contexts [14]. The first hypothesis, presented by Espinoza, was that the change was based on analogy to other contexts, such as polite commands or the apodosis of si-clauses, where the conditional already alternated with the imperfect subjunctive [10]. Silva-Corvalán rejects this hypothesis as inadequate, arguing that "analogy is not the cause of change but provides the patterns according to which change takes place" [14] (p. 90). The second hypothesis, that of Lavandera, is that the loss of the future subjunctive and the subsequent extension of the imperfect subjunctive to cover both hypothetical contrariness-to-fact and hypothetical possibility in the future creates ambiguity, which is then resolved by using the conditional form to mark higher belief in the possibility of an outcome [9]. Silva-Corvalán calls this explanation "insufficient" [14] (p. 92), since it does not explain why it was not the present subjunctive-also useable to talk of future possibility-which was extended rather than the imperfect form. Additionally, the conditional was reported in these contexts before the disappearance of the future subjunctive; thus, if a distinction between the two domains had been necessary, the future subjunctive should have been retained. Finally, Lavandera's explanation is limited to hypothetical si-clauses, though the extension occurs in many other contexts as well.

1 Rojo and Vázquez Rozas's reported figures include indicative uses of -ra, not uncommon in Galicia, thus artificially inflating the percentage of $-r a(73.34 \%)$ that is reported to be in variation with -se [2]. Thus the exact percentage of -se use in truly variable contexts is not known, but is clearly over $27 \%$.

2 In fact, there is some variable use of - $r a$ in imperfect subjunctive contexts in Galicia, reaching around $18 \%$ in written texts and possibly more extended in spoken language, but this use is not considered "correct" in normative Galician [2]. 
In lieu of these two explanations, Silva-Corvalán promotes a hypothesis of complex causation in which it is a combination of semantic ambiguity and language contact that causes the shift [12]. She postulates that the shift of -ra, which as Espinoza noted historically alternated with conditional forms in certain contexts, from indicative to subjunctive caused a lack of clarity in the meaning difference between subjunctive forms in -ra and indicative forms in -ría [14,15]. Additionally language contact plays a role, she claims, as in Lavandera's study it was Spanish speakers of Italian origin, and in her own study Spanish speakers of Basque background, who most frequently employed the conditional forms in a parallel manner to their language-of-origin.

Though Silva-Corvalán's hypothesis was specifically regarding the extension of conditional to imperfect subjunctive contexts, her arguments can logically be extended also to -se/-ra variation. She argues that "given two forms, one indicative and one subjunctive, with almost identical meaning and distribution, the universal tendency is for the subjunctive form to fall into disuse, probably because of an overall lower frequency of occurrence in discourse" [14] (p. 92). This appears to be the same historical trend followed by verb forms in -se and -ra: while the -ra was originally indicative, as its meaning drew closer to that of -se and it took on subjunctive modality, it came to predominate over -se perhaps because it still retained some indicative presence that lent it higher frequency of use. It can be further hypothesized that, if influence from parallel structures in Basque and Italian could accentuate and accelerate a shift to conditional, contact between Spanish and a language such as Galician that retains the modality difference between -se and -ra might impede the ongoing shift from the former to the latter in imperfect subjunctive contexts. Conversely, the shift in Castilian might pass over and become the norm in Galician as well.

Because Galician and Castilian are typologically similar languages, having developed from closely related varieties of late Latin spoken in the Peninsula, it can be expected that both would be highly permeable with respect to influences from one another [16]. However, predictions as to the type, extent, and direction of influence are not always easy to make based on language contact theory. Thomason and Kaufman's framework, for example, predicts differing results of contact between two languages based on whether speakers are maintaining their original language, in which case they may borrow lexical and perhaps structural items from the other language, or are shifting to the new language, in which case their former language can be expected to "interfere" with many levels of the target language [16]. Similarly, Van Coetsem talks about contact effects being determined by the agency of speakers who are dominant in one of the two languages [17]. If speakers are dominant in the receiving language, they will borrow elements from the source language and incorporate them in their language use. If speakers are dominant in the source language, however, they will impose structural (and sometimes lexical) elements of their dominant language onto their weaker, receptive language.

It is difficult to apply these theoretical constructs in a systematic way to the contact situation in Galicia for two reasons. First, because many speakers in the region grow up bilingual, determining which language is dominant, and therefore agentitive in Van Coetsem's framework, is often unfeasible. Second, although the historical choice in the region would have been between maintenance of Galician or shift to Castilian, a reverse shift is also occurring. Many younger speakers who were raised predominantly in Castilian are choosing to adopt Galician as their nearly exclusive operating language, to show pride in and solidarity with regional identity (see, for example, Ramallo [18] for further discussion of these neofalantes 'new speakers').

More promising in such a context are the possible indications of transfer between languages in contact presented in Silva-Corvalán [19]. Without constraining the direction in which transfer can occur between languages, she describes the following conditions (among others) that may indicate such transfer:

- When two languages $X$ and $Y$ share a structurally similar form but with different meanings, the meaning of the form in language $X$ may become associated with the parallel form in language $\mathrm{Y}$, even if language $\mathrm{Y}$ already has a different form with the same meaning. 
- When two forms in language $\mathrm{Y}$ are in competition, a contact-variety of language $\mathrm{Y}$ may have more frequent use of the form that is most similar to that of language $\mathrm{X}$, as compared to a possibly categorical or highly preferred alternate form in non-contact varieties.

In Galician, as previously described, the morpheme - $r a$ is used to mark the simple pluperfect verb form, which corresponds in meaning to the Castilian habia 'I had' + past participle construction, while in Castilian the -ra morpheme is one of two possible markers of the imperfect subjunctive. Thus, based on Silva-Corvalán's conditions just described, the following two phenomena, if found to hold true for the Spanish spoken in Galicia, may indicate transfer from Galician to Castilian:

1. The - $r a$ morpheme in the Castilian of Galicia may take on the perfective meaning of the Galician -ra form (attested in Rabanal, Pollán [20,21]).

2. The -se ending of imperfect subjunctive, far less frequent than the -ra ending in most varieties of Spanish including that of Madrid [22], may be more common in Galicia, where it is analogous to the -se ending of the Galician imperfect subjunctive.

It is on the second of these two possibilities that the present study focuses.

\subsection{Variation between -ra and -se in Galicia}

Some investigation of patterns in imperfect subjunctive form in the Spanish spoken in Galicia has been carried out previously. Kempas, for example, included Galicia in his study of -se/-ra variation in 14 regions in Spain [13]. Using fill-in-the-blank elicitation exercises, he examined not only the frequency of each variant in participant responses, but also considered whether and how many participants used one or the other variant categorically. In comparison to other regions, Galicia yielded the highest percentages of -se usage (44.4\%, compared with $22.9 \%$ overall) and also had the lowest overall rate of categorical use (34.8\%, compared with approximately $60 \%$ categorical use nationwide). Of the eight Galicians whose choice of form was categorical, five used only the - $r a$ form. This predominance of categorical - $r a$ fits with the general tendency Kempas noted overall: "la tendencia de incluso aquellos que prefieren cantase a utilizar también cantara de vez en cuando" [13] (p. 253). That is, many of those who use -se forms will also at times use -ra, while several of those who prefer the latter form will never employ the former. Though this trend is less dramatic in Galicia than in other parts of Spain it does still hold, indicating that idiosyncratic tendencies should be taken into account in studies of this phenomenon.

Rojo and Vázquez Rozas studied this issue in oral data using a corpus of interviews of educated speakers, thus also including sociolinguistic factors in their analysis [2]. They found that men and youth tended to favor the -se form more than women and older speakers. However, when they looked at the data for each individual, they discovered that examining overall response rates by group could be highly misleading. Individuals tended to use one form or the other heavily, and each grouping of age and gender tended to contain at least one individual whose preference was -se and another whose categorical choice was -ra. The only exception to this was the oldest group of women, all three of whom showed a marked preference for - $r a$. Despite this split, however, there was still an evident predominance of - $r a$ forms, as $75 \%$ of those who used - $r a$ preferentially completely excluded -se from their usage, while none of those who preferred -se used this form exclusively. This corresponds neatly to the findings in Kempas [13].

\subsection{Si-Clauses Studied Elsewhere}

Lavandera carried out a study on si-clause variation in Buenos Aires Spanish [9]. She considered present indicative, imperfect subjunctive, and conditional as possible protasis variants, and present indicative and conditional as options in the apodosis. She also examined the occurrence of each of the six combinations with respect to degree of probability of the event being discussed. Thus she found that the present tense in the protasis was heavily linked to statements viewed as facts or 
nearly facts, the imperfect subjunctive was favored when statements were clearly contrary to reality, and the conditional was favored in those in-between cases that were neither highly probable nor clearly impossible.

Though her dissertation research grouped both imperfect subjunctive forms together in studying the protasis of si-clauses, Lavandera does include an analysis of -se/-ra variation in an appendix [9]. In her study, the primary users of the -se form were male, middle-aged, and non-college-educated speakers. Linguistically, -se was more frequently employed as the auxiliary in a compound verb form and in a structure headed by como si 'as if'. Thus, though the author does not note any semantic difference between forms, she does indicate that -se "may be somewhat more resistant to banishment from the language in contexts where the unreal meaning is especially emphasized" [9] (p. 372).

In her study in Covarrubias, Spain, Silva-Corvalán noted large-scale replacement of the imperfect subjunctive by the conditional in the protasis of si-clauses, more accentuated in those under 30 but reaching upwards of $70 \%$ for all ages and both genders [23]. She also examined verb tense choice in the apodosis of these clauses, and noted the incursion of the imperfect indicative in this traditionally conditional context, particularly in female speech. She described a "principle of distance" as the guiding factor behind these shifts; because the forms in question are closely related, "the form which is farthest away from the speaker, in the sense that it refers to objects or events which are the farthest from him in his objective (e.g., actual distance) or subjective (e.g., possibility of actualization) world, will be lost" [23] (p. 596).

A further element of her study was to carry out a pseudo-matched guise task with participants to determine social attitudes toward the use of conditional for imperfect subjunctive. Her findings indicate that the imperfect subjunctive is associated with higher education and more status, but that there appears to be covert prestige associated with the conditional in that judgements of personality tended to be higher for this variant; thus participants' attitudes do appear to pattern similarly to their production.

While these two are not the only studies to have been carried out on conditional statements, they were highly influential in the design of the present study and are thus particularly relevant to mention. For a more exhaustive review of the (often contradictory) results found throughout the literature, see Anderson's dissertation, for which the study herein described served as a pilot [24].

What follows is a case study comparing production and acceptance of verb forms in hypothetical statements by 29 speakers of Galician Spanish.

\section{Materials and Methods}

\subsection{Participants}

In total 29 individuals- 5 males and 24 females-participated in this study. Fourteen were under the age of 25, eleven were between the ages of 26 and 40, and the remaining four were older than 40, with the oldest participant age 55.3,4 One individual had only completed elementary education, four had secondary education, sixteen had at least some university experience, and eight had pursued graduate studies. The specific breakdown of participants across these groups is shown in Table 1.

Language background was quite varied, though no participant indicated exclusive use of Castilian in all areas of their life and only three indicated exclusive use of Galician (though these three were fully able to carry out the assigned written task in Castilian). Participants were solicited via email and social media through mutual contacts. ${ }^{5}$

3 Note: while Age is treated as a continuous variable in the statistical analysis, it is rendered categorically here for the purpose of inclusion in Table 1.

4 Capitalization of the words Age, Education, Possibility, Protasis, etc., is used to indicate reference to a variable name.

5 As approved by the University of Minnesota's Institutional Review Board, participants were informed before completing the study that their participation implied consent for their responses to be used in presentations and publications arising therefrom. 
Table 1. Breakdown of participants by Sex, Age, Education.

\begin{tabular}{|c|c|c|c|c|c|c|c|c|c|c|c|c|c|c|c|c|c|}
\hline Sex & \multicolumn{9}{|c|}{ Male } & \multicolumn{8}{|c|}{ Female } \\
\hline Age & \multicolumn{3}{|c|}{$<25$} & \multicolumn{3}{|c|}{$26-40$} & \multicolumn{3}{|c|}{$40+$} & \multicolumn{3}{|c|}{$<25$} & \multicolumn{3}{|c|}{$26-40$} & \multicolumn{2}{|r|}{$40+$} \\
\hline Education & $S$ & $\mathrm{U}$ & G & S & $\mathrm{U}$ & G & S & $\mathrm{U}$ & G & S & $\mathrm{U}$ & $\mathrm{G}$ & S & $\mathrm{U}$ & G & S & U G \\
\hline & & 2 & 1 & & 1 & 1 & & & & 2 & 7 & 2 & 1 & 4 & 4 & 2 & 2 \\
\hline
\end{tabular}

$\mathrm{S}=$ secondary or less, $\mathrm{U}=$ undergraduate, $\mathrm{G}=$ graduate.

\subsection{Tasks}

Participants completed an Internet-based form with two parts in Castilian. The first was a background questionnaire designed to elicit demographic information as well as their reported language use. The second was an acceptability task consisting of twenty-four conditional statements. The verb form in the protasis rotated between imperfect subjunctive in - $r a$, imperfect subjunctive in -se, conditional, and present, while the form in the apodosis was either conditional, imperfect, or present. Additionally, half of the conditions were clearly contrary-to-fact (e.g., Si yo fuera tú... 'If I were you ... '), while the other half were not clearly contrary-to-fact (e.g., Si yo ganase la lotería ... 'If I won the lottery ... '). The composition of the 24 sentences is summarized in Table 2.

Participants were asked to rate a series of three statements related to each sentence on a four-point descriptive scale, with options being "I completely disagree", "I more-or-less disagree", I more-or-less agree", and "I completely agree". The series of statements rated for each sentence was:

1. I know people who would say this in this way.

2. I would say this in this way.

3. It is correct to say this in this way.

If participants responded that they disagreed with statements 2 or 3, they were then asked to reformulate the phrase so that it would be correct and/or something they themselves would say. In total, 662 response tokens were obtained for each of these three statements.

Table 2. Statement composition.

\begin{tabular}{|c|c|c|c|c|c|c|c|c|c|}
\hline & \multicolumn{8}{|c|}{ Protasis } & \multirow[b]{3}{*}{ Total } \\
\hline & \multicolumn{4}{|c|}{ Contrary-to-Fact } & \multicolumn{4}{|c|}{ Not Contrary-to-Fact } & \\
\hline & $-r a$ & $-s e$ & Cond & Pres & $-r a$ & $-s e$ & Cond & Pres & \\
\hline \multirow{3}{*}{ Apodosis } & 1 & 1 & 1 & 1 & 1 & 1 & 1 & 1 & 8 \\
\hline & 1 & 1 & 1 & 1 & 1 & 1 & 1 & 1 & 8 \\
\hline & 1 & 1 & 1 & 1 & 1 & 1 & 1 & 1 & 8 \\
\hline \multirow[t]{2}{*}{ Totals } & 3 & 3 & 3 & 3 & 3 & 3 & 3 & 3 & 24 \\
\hline & \multicolumn{4}{|c|}{ Total C-t-F: 12} & \multicolumn{4}{|c|}{ Total Not C-t-F: 12} & \\
\hline
\end{tabular}

C-t-f: contrary-to-fact; Cond: conditional; imp: imperfect; pres: present.

In addition to the two tasks described above, three participants completed an additional written task, the analysis of which is not included in this paper.

\subsection{Dependent Variables}

Three dependent variables were considered in this study. The first two, Correctness and Social Acceptability, were calculated numerically from responses on the task by assigning a value of -2 to responses of "I completely disagree", 2 to responses of "I completely agree", and -1 and 1 to "I more-or-less disagree/agree", respectively (there was no middle option/zero value). A paired $t$-test 
was then run on participant responses to each of the three statements mentioned above; differences between statements 1 and 2 and between statements 1 and 3 were significant at the $p=0.01$ level, while the difference between statements 2 and 3 were not significant at this level. Thus, the responses to statement 2 were omitted, the Correctness variable for each token corresponded to the response to the third statement on the questionnaire, and the Social Acceptability variable corresponded to the response to the first of these statements.

The third dependent variable, based solely on the 486 reformulations of unacceptable phrases, was whether the participant had chosen the -se form or the -ra form in their reformulation. The one reformulation that contained a present-tense form in the protasis was excluded from analyses involving this variable.

\subsection{Independent Variables}

Several independent social variables were considered in this analysis. The first, Age, was approximated numerically by subtracting the participant's birth year from 2015, the year in which the data were obtained.

Intimate and Public language use were also considered independent variables. These were calculated as an average of participant responses to the questions on language use. A response of "Only Castilian" was scored as a -2, while "Only Galician" was scored as a 2, with the other responses falling naturally in between; thus, the more positive the score, the greater the preference for Galician over Castilian, and vice-versa. The scores for primary language, language use with family, and language use with friends were averaged to create a composite score for language use in intimate settings, and similarly, language use at school/work and in the community were averaged to give a composite public language score. ${ }^{6}$ Finally, participant Sex and level of Education were also included as independent variables.

In addition to these social variables, several linguistic variables were considered. The first was verb form in the statement Protasis. While in the acceptability task this involved possible values of $-s e,-r a$, conditional, or present indicative, only those tokens containing -se or -ra are included in the statistical analysis. A set of pairwise t-tests indicated that highly significant differences $(p<0.001)$ existed between ratings of statements with conditional protasis, present protasis, and an imperfect subjunctive protasis (whether -se or - $r a$ ), but that differences between -se and -ra were not significant $(p>0.7)$. This held for the both Correctness and Social Acceptability dependent variables; mean ratings and standard deviations for each of these are given in Table 3. Thus, since the purpose of this study is to examine potential differences between -se and $-r a$, it was considered that including the other two (highly dispreferred) protasis forms might obscure any smaller differences between the two imperfect subjunctive forms.

Table 3. Mean ratings and standard deviations by Protasis form.

\begin{tabular}{ccccccccc}
\hline & \multicolumn{2}{c}{$-s e$} & \multicolumn{2}{c}{$-r a$} & \multicolumn{2}{c}{ Present } & \multicolumn{2}{c}{ Conditional } \\
\cline { 2 - 9 } & $\mathbf{M}$ & SD & M & SD & M & SD & M & SD \\
\hline Social Acceptability & -0.13 & 1.81 & -0.11 & 1.81 & -0.74 & 1.59 & -1.58 & 1.02 \\
Correctness & -0.69 & 1.81 & -0.64 & 1.76 & -1.43 & 1.24 & -1.96 & 0.33 \\
\hline
\end{tabular}

Verb form in the statement Apodosis was considered as an independent variable, with possible values of conditional, imperfect, or present indicative. Following Lavandera, the Possibility of the

6 Aside from being logical from a social standpoint, these groupings are somewhat justified in that the median rating for each of the three Intimate language categories was -1 , while the median rating for each of the two Public language categories was zero. However, it should be noted that the mean values for each of these five categories did not differ significantly at the $p=0.01$ level. 
protasis statement was taken into account, with "contrary-to-fact" and "not contrary-to-fact" as possible values [9].

Finally, in the analysis of the third dependent variable (-se/-ra response), which included only phrases produced by participants as reformulations, the form of the verb in the rejected sentence from which the reformulation was derived (i.e., the form serving as a Prime) was considered an independent variable.

\section{Results}

A series of multivariate analyses on the variables described previously was carried out using the statistical software R. The results of these three analyses are described in the following sections, and tables with the corresponding statistical outputs are included in the Appendix A.

\subsection{Social Acceptability and Correctness}

The analysis of the Social Acceptability dependent variable was carried out in R using an ordinal logistic regression in which both the individual participant and the prompt statement were treated as random effects variables. In this analysis, participant Age and the Apodosis form were significant correlates of Social Acceptability $(p<0.01)$, with older participants indicating greater statement acceptance over all as shown in Figure 1, while apodoses in imperfect $(M=-0.91, S D=1.59)$ or present $(\mathrm{M}=-1.13, \mathrm{SD}=1.39)$ corresponded to lower acceptance rates than conditional apodoses $(\mathrm{M}=0.11$, $\mathrm{SD}=1.83)$.

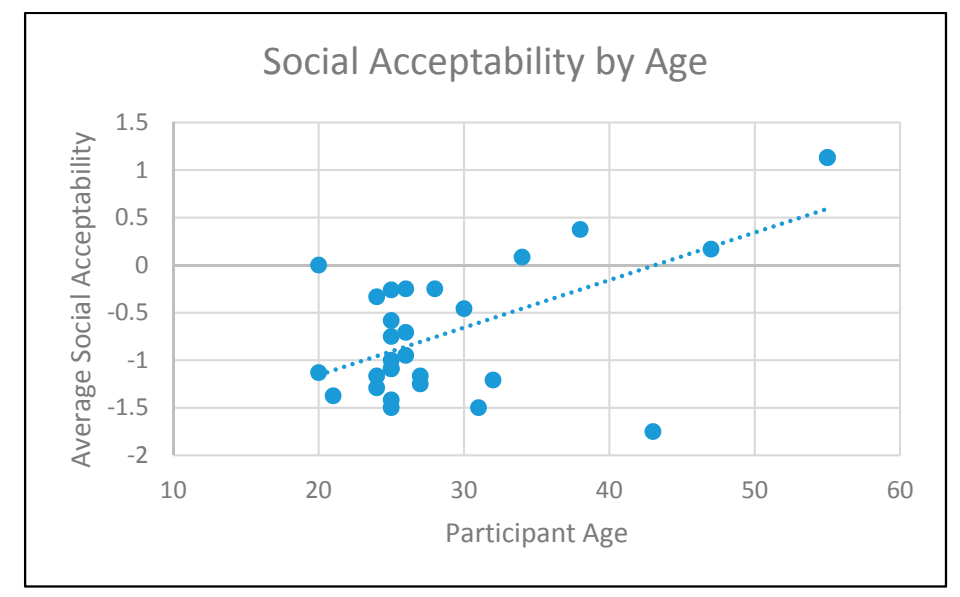

Figure 1. Social Acceptability ratings by Age.

However, more relevant to the purpose of this study is the interaction (or lack thereof) between dependent variables and the Protasis form. For this dependent variable, the form in the protasis did not significantly condition a statement's Social Acceptability, nor were there any significant interactions between Protasis form and other independent variables. This indicates that the Social Acceptability of protases in -se or - $r a$ is not conditioned by the social or linguistic variables considered.

The results for Correctness, examined using the same statistical methods used for Social Acceptability, were similar to those just described. The Apodosis form was a significant correlate of phrase Correctness ratings $(p<0.001)$, with imperfect $(\mathrm{M}=-1.62, \mathrm{SD}=1.04)$ or present $(\mathrm{M}=-1.72$, $\mathrm{SD}=0.88)$ apodoses rated as far less correct than those containing the conditional form $(\mathrm{M}=-0.19$, $\mathrm{SD}=1.90$ ). Age was not a significant predictor of Correctness at the $p=0.01$ level, however, and like before, neither Protasis nor the interaction between Protasis and other independent variables were significant. 


\subsection{Choice of -se/-ra}

The final analysis was carried out using only data from participant corrections of unacceptable statements, with the purpose of discovering which factors appear to contribute most to choice between -se and $-r a$ in the protasis of conditional statements. As previously indicated, only one reformulation contained a verb in a form other than imperfect subjunctive in the protasis; this token was excluded from the present analysis. An additional independent variable, the verb form in the model protasis (i.e., the Prime), was added to this analysis in order to reveal possible effects of priming from the model on the choice of form.

A logistic regression model with random effect for individual was carried out on the resulting data set. Prime was the only significant predictor of -se use $(p<0.001)$. A post-hoc Tukey test revealed that a -se in the model led strongly to maintenance of the same form in the correction, while -ra, conditional, or present in the model disfavored it.

This indicates a priming effect, with both -se and -ra more likely to be maintained in reformulations if present in the model sentence, though surprisingly, $-r a$ was still only maintained in $47 \%$ of reformulations.

Figure 2 shows how these priming effects played out for each individual participant. ${ }^{7}$ While some tendencies, such as the greater number of categorical productions of -se when presented with a -se prime, are evident in the image, the most notable result is the great variability in production rates across participants. Thus, in comparison to the overall acceptance of both forms which is remarkably uniform across all participants, production shows great idiosyncratic variability.

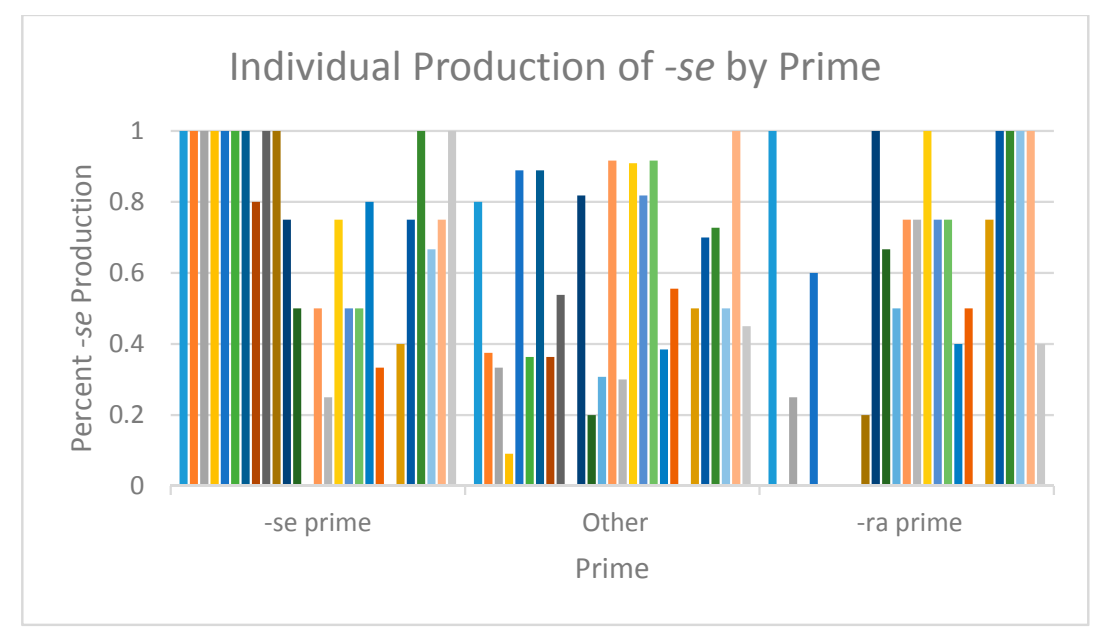

Figure 2. Production of -se by priming effects.

\section{Discussion}

Linguistically, the si-clause system in Galicia appears to correspond heavily to Castilian prescriptive norms. Both -se and -ra were generally accepted in the protasis of conditional statements. Unlike the results of Lavandera in Buenos Aires and Silva-Corvalán in Covarrubias, the conditional appears to be almost categorically rejected in Galician Spanish (with an average rating of -1.96 , where -2 was the lowest possible response) $[9,23]$. This could be due in part to the strong maintenance of -se in the region; if - $r a$ has not become the overwhelming and nearly exclusive subjunctive marker in Galicia that it is in other regions, there may be less cause for the conditional to encroach on this domain.

7 Only data for -se are shown in the figure, but as -se and -ra were the only forms produced, those tokens not produced as -se were produced as $-r a$, and the relevant percentages for - $r a$ production can be obtained by subtracting the -se percentages from 100 . 
Unlike results in Lavandera [9], Possibility of the event in the si-clause did not significantly condition form choice in this study. There are a few possibilities to explain this difference. First, Lavandera's finding was that statements that were neither presumably factual nor clearly contrary-to-reality were closely associated with conditional use. Because the conditional is so heavily rejected in the protasis in Galician Spanish, this same association could not occur, and it may be that neither of the commonly accepted forms has taken on this pragmatic function. On the other hand, Lavandera's data was taken from spontaneous speech, and she was able to use discursive and contextual cues to determine the relative reality of each statement for her participant, while in this study statements were prefabricated. Thus, while it was possible to create statements that were clearly contrary-to-reality, it was not possible to distinguish between the categories of nearly factual and ambivalent statements. This lack of distinction could have nullified any existing correlation between Possibility and Protasis form in the present data.

A final linguistic factor than needs to be taken into account in future investigation is the possible effect of priming on form production. Clear differences were found in production of forms primed with -se, when compared to other forms. This could indicate that, when both forms are acceptable in a region, use of a form by an interlocutor could lead to accommodation and use of the same form that, while accepted by the participant, would not otherwise be normally produced as frequently in unprimed context.

Overall, social factors were not shown to have an impact on either form acceptability or production, as neither Age, Public, nor Intimate Language use significantly conditioned participant response in this way. This could indicate that the variation between the two forms is relatively stable and that neither form is considered more or less "correct" than the other, as well as that neither form is specifically associated with those who speak Galician.

This lack of correspondence somewhat contradicts the simple hypothesis that the influence of the Galician language is what facilitates maintenance of the -se form in the region. Language contact may still have an impact, however. Because the - $r a$ form has different functions in Castilian and Galician, it is arguably the more complex of the two forms for speakers of Galician Spanish. Because of this, the surprising trend for -ra-primes to lead to the reproduction of the -ra form in just under half of reformulations may be a symptom of a greater uncertainty for bilinguals in navigating appropriate use of the $-r a$ form in their two languages, particularly as research has shown that bilinguals have both of their languages (and thus in this context both competing functions of the -ra form) activated when producing and processing either language [25]. However, it is important to note that idiosyncratic differences did have an extremely large part to play in the choice of verb form, just as they did in Kempas and Rojo and Vázquez Rozas [2,13], so conclusions drawn from aggregate results remain tentative at.

Curiously, individual differences in this study did not follow the same trend noted by Kempas [13]. While in his study -ra dominance favored exclusivity and -se dominance favored variation, these polarizing effects were not found in this study, as all participants save one exhibited some variation. Indeed, those that produced primarily -se appeared to have less variation than those who produced -ra preferentially. More research is needed to determine how these trends (or lack thereof) play out in society at large.

\section{Conclusions}

The results of this study indicate a high overall maintenance of the imperfect subjunctive in -se in Galicia. The overall rate of unprimed production of -se, $52.7 \%$, differs only slightly from the $44.4 \%$ rate documented by Kempas [13]. However, as documented by both Kempas and Rojo and Vázquez Rozas, considering overall rates for each form could be misleading [2,13]. Individual differences appear to strongly condition the data, and thus should be accounted for in future studies.

Though social factors were not generally significant in this study, the small number of participants and the paucity of males involved makes it possible that differences will emerge in a larger study. 
Additionally, a study including more participants should examine the effects of socioeconomic status and rural versus urban living to determine whether these may have effects that have not yet been noted. Language use should continue to be investigated as a possible factor, as in this study it was difficult to disentangle language use from individual idiosyncrasies.

The examination of linguistic factors indicates that the verbal system of Galician Spanish, at least in this respect, is in line with prescribed norms. No indications of pragmatic difference between -se and - $r a$ were found in this study; given the information obtained thus far, the two do appear to be pragmatically equivalent. However, data involving spontaneous speech should be obtained in order to cast more light on possible distinctions between the two.

Finally, given the discrepancies between acceptance of forms, which was relatively standard across all participants, and production of forms, which showed strong individual differences, it is recommended that future studies consider and compare both production and acceptability. Additionally, a comparison should be made between oral and written language, to determine whether forms are used differentially in different modes. A study examining involving these four elements-production and perception of both oral and written language-could reveal important nuances of individual and societal attitudes and behaviors in Galicia.

Conflicts of Interest: The authors declare no conflict of interest.

\section{Appendix A}

Table A1. Social Acceptability ordinal logistic regression with random effects for Individual and Phrase-Analysis of Deviance table.

\begin{tabular}{lccc}
\hline & LR Chi Sq & Df & $p$-Value \\
\hline Protasis (n.s.) & 0.09 & 1 & 0.76 \\
Gender (n.s.) & 2.07 & 1 & 0.15 \\
Age** & 16.63 & 1 & 0.00 \\
Education (n.s.) & 6.13 & 3 & 0.94 \\
Apodosis ** & 27.64 & 2 & 0.00 \\
Possibility * & 5.58 & 1 & 0.02 \\
Intimate Language (n.s.) & 0.56 & 1 & 0.45 \\
Public Language (n.s.) & 0.45 & 1 & 0.50 \\
Protasis *Gender (n.s.) & 0.27 & 1 & 0.60 \\
Protasis *Age (n.s.) & 0.12 & 1 & 0.73 \\
Protasis *Education (n.s.) & 1.19 & 3 & 0.76 \\
Protasis *Apodosis (n.s.) & 2.02 & 2 & 0.36 \\
Protasis *Possibility (n.s.) & 1.25 & 1 & 0.26 \\
Protasis *Intimate Lang (n.s.) & 0.14 & 1 & 0.70 \\
Protasis *Public Lang (n.s.) & 0.04 & 1 & 0.84 \\
\hline -264.95, AIC = 581.90 (for the associated Ordinal Logistic Regression) ${ }^{* *}=$ significant, $^{*}=$ \\
cance, (n.s.) = non-significant. & \multicolumn{4}{|}{}
\end{tabular}

Table A2. Correctness ordinal logistic regression with random effects for Individual and Phrase-Analysis of Deviance table.

\begin{tabular}{lccc}
\hline & LR Chi Sq & Df & $p$-Value \\
\hline Protasis (n.s.) & 0.32 & 1 & 0.57 \\
Gender (n.s.) & 0.14 & 1 & 0.71 \\
Age (n.s.) & 2.92 & 1 & 0.09 \\
Education (n.s.) & 1.93 & 3 & 0.59 \\
Apodosis ** & 25.36 & 2 & 0.00 \\
Possibility (n.s.) & 1.79 & 1 & 0.18 \\
Intimate Language (n.s.) & 0.63 & 1 & 0.43 \\
Public Language (n.s.) & 0.01 & 1 & 0.93 \\
\hline
\end{tabular}


Table A2. Cont.

\begin{tabular}{lccc}
\hline & LR Chi Sq & Df & $p$-Value \\
\hline Protasis *Gender (n.s.) & 0.04 & 1 & 0.85 \\
Protasis *Age (n.s.) & 2.34 & 1 & 0.13 \\
Protasis *Education (n.s.) & 3.57 & 3 & 0.31 \\
Protasis *Apodosis (n.s.) & 1.18 & 2 & 0.55 \\
Protasis *Possibility (n.s.) & 0.11 & 1 & 0.74 \\
Protasis *Intimate Lang (n.s.) & 0.29 & 1 & 0.59 \\
Protasis *Public Lang (n.s.) & 0.42 & 1 & 0.52 \\
\hline
\end{tabular}

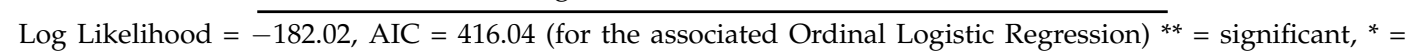
approaches significance, (n.s.) = non-significant.

Table A3. Corrections logistic regression with random effect for Individual-ANOVA table.

\begin{tabular}{cccc}
\hline & Df & Sum Sq & F-Value \\
\hline Prime** & 3 & 10.25 & 3.42 \\
Possibility (n.s.) & 1 & 0.29 & 0.29 \\
Gender (n.s.) & 1 & 0.01 & 0.01 \\
Age (n.s.) & 1 & 0.16 & 0.16 \\
Education (n.s.) & 3 & 8.34 & 2.78 \\
Intimate Language (n.s.) & 1 & 0.65 & 0.65 \\
Public Language (n.s.) & 1 & 0.23 & 0.23 \\
\hline
\end{tabular}

Marginal R2 = 0.11; Conditional R2 = 0.27; Log Likelihood = -296.6, AIC 619.2 (for the associated Logistic Regression) ${ }^{* *}=$ significant,${ }^{*}=$ approaches significance, (n.s.) $=$ non-significant.

\section{References}

1. Veiga, A. La Forma Verbal Española "Cantara" en su Diacronía; Universidade de Santiago de Compostela: Santiago de Compostela, Spain, 1996.

2. Rojo, G.; Vázquez Rozas, V. Sobre las formas en -ra en el español de Galicia. In Perspectives in the Study of Spanish Language Variation. Papers in Honor of Carmen Silva-Corvalán; Enrique-Arias, A., Gutiérrez, M.J., Landa, A., Ocampo, F., Eds.; Universidade de Santiago de Compostela: Santiago de Compostela, Spain, 2014; pp. 237-270.

3. Hermerén, I.; Lindvall, L. La distribución de las formas en ra y se en un texto español moderno. Mod. Spr. 1989, 83, 34-42.

4. Carbonero Cano, P. Usos de las formas verbales en -ra y en -se en el habla de Sevilla (nivel popular). In Habla de Sevilla y Hablas Americanas; Carbonero Cano, P., Palet Plaja, M.T., Eds.; Universidad de Sevilla: Sevilla, Spain, 1990; pp. 45-58.

5. Bolinger, D.L. Subjunctive -ra and -se: "Free variation"? Hispania 1956, 39, 345-349. [CrossRef]

6. Serrano Montesinos, M.J. El subjuntivo -ra y -se en oraciones condicionales. Estud. Filol. 1996, 31, $129-140$.

7. Gili Gaya, S. Curso Superior de Sintaxis Española, 11th ed.; Vox: Barcelona, Spain, 1973.

8. Williams, A. The use of the -ra and -se forms of the past subjunctive in Navarre. Hispania 1982, 65, 89-93. [CrossRef]

9. Lavandera, B.R. Linguistic Structure and Sociolinguistic Conditioning in the Use of Verbal Endings in si-Clauses (Buenos Aires Spanish). Ph.D. Thesis, School of Arts and Sciences, University of Pennsylvania, Philadelphia, PA, USA, 1975.

10. Moreno de Alba, J.G. Valores de las Formas Verbales en el Español de México; UNAM: Mexico City, México, 1978.

11. Navarro, M. La alternancia -ra/-se y -ra/-ría en el habla de Valencia (Venezuela). Thesaurus-Instituto Caro y Cuervo 1990, 45, 481-488.

12. Rojo, G. Sobre la distribución de las formas llegara y llegase en español actual. In Scripta Philologica in Memoriam Manuel Toboada Cid; Casado Velarde, M., Ed.; Universidade da Coruña: A Coruña, Spain, 1996; pp. 677-691.

13. Kempas, I. Sobre la variación en el marco de la libre elección entre cantara y cantase en el español peninsular. Moenia 2011, 17, 243-264. 
14. Silva-Corvalán, C. Conditional for subjunctive in Old Castile. In Proceedings of the Eighth Annual Meeting of the Berkeley Linguistics Society, Berkeley, CA, USA, 13-15 February 1982; pp. 87-96.

15. Espinoza, A. The use of the conditional for the subjunctive in Castilian popular speech. Mod. Philol. 1930, 27, 445-449. [CrossRef]

16. Thomason, S.G.; Kaufman, T. Language Contact, Creolization, and Genetic Linguistics; University of California Press: Berkeley, CA, USA, 1988.

17. Van Coetsem, F. A General and Unified Theory of the Transmission Process in Language Contact; Winter: Heidelberg, Germany, 2000; Volume 19.

18. Ramallo, F. Neofalantismo. In Contacto de Linguas, Hibrididade, Cambio: Contextos, Procesos e Consecuencias; Gugenberger, E., Monteagudo, H., Rei-Doval, G., Eds.; Consello da Cultura Galega: A Coruña, Spain, 2013; pp. 245-258.

19. Silva-Corvalán, C. Language Contact and Change: Spanish in Los Angeles; Clarendon Press: Oxford, UK, 1994.

20. Rabanal, M. Gramática breve del castellano hablado en Galicia y otros temas. In Hablas Hispánicas: Temas Gallegos y Leoneses; Rabanal, M., Ed.; Alcalá: Madrid, Spain, 1967; pp. 11-69.

21. Pollán, C. The expression of pragmatic values by means of verbal morphology: A variationist study. Lang. Var. Chang. 2001, 13, 59-89. [CrossRef]

22. Nowikov, N. El valor doble de la forma en -se en el español peninsular y americano. Ibero-Americana Pragensia 1984, 18, 61-66.

23. Silva-Corvalán, C. The social profile of a syntactic-semantic variable: Three verb forms in Old Castile. Hispania 1984, 67, 594-601. [CrossRef]

24. Anderson, A. Receding or Resurgent? On the Use of Cantase (and Cantara) in Galician Spanish. Ph.D. Thesis, University of Minnesota, Minneapolis, MN, USA, 2017.

25. Kroll, J.F.; Bialystok, E. Understanding the consequences of bilingualism for language processing and cognition. J. Cogn. Psychol. 2013, 25, 497-514. [CrossRef] [PubMed]

(C) 2017 by the author. Licensee MDPI, Basel, Switzerland. This article is an open access article distributed under the terms and conditions of the Creative Commons Attribution (CC BY) license (http:/ / creativecommons.org/licenses/by/4.0/). 